\title{
Palm oil and derivatives: fuels or potential fuels?
}

\author{
Daniel PIOCH ${ }^{1}$ \\ Gilles VAITILINGOM ${ }^{2}$ \\ ${ }^{1}$ Cirad-Amis Department, \\ UMR 64 Process Engineering and Bioproducts \\ Development, Cirad TA/4016, \\ 34398 Montpellier Cedex 5, \\ France \\ ${ }^{2}$ Cirad-Foret Department, \\ UPR 42 Biomass and Energy, Cirad TA/4015, \\ 34398 Montpellier Cedex 5, \\ France
}

\begin{abstract}
Scientific and technical information including field trials about uses of palm oil as fuel has been available for more than half a century now. Several ways were investigated, from the simple mixture with petroleum Diesel fuel, to more sophisticated solutions. The quality of vegetable oils in natura as fuel is difficult to assess because of interferences between properties of the triacylglycerols - the main components - and those of the many minor components, their content varying significantly from sample to sample. A methodology set up at Cirad allowed to investigate separately natural triacylglycerols alone and the effect of minor components. In addition to these laboratory experiments, engine test at bench and field trials performed in palm oil producing countries, show that this oil is among the best oils as fuel ; palm kernel oil whose chemical and physical properties are very close to those of the best of the series investigated, namely copra oil, should display also very interesting properties as Diesel biofuel. Both oils do require external adaptation of the engine when using an indirect injection type engine but even heavier adaptations for a direct injection model. Thus for use as Diesel fuel palm and palm kernel oils are suitable for captive fleets or for engine gensets, to balance the adaptation cost by a scale-up effect either on the number of identical engines or on the nominal vegetable oil consumption per set. Direct use of palm et palm kernel oils fits very well with technical and economical conditions encountered in remote areas. It is also possible to mix palm oil to Diesel fuel either as simple blend or as micro-emulsion.

Out of the direct use, palm oil methyl or ethyl ester, often referred to as biodiesel, displays properties similar to those of petroleum Diesel fuel. This technical solution which is suitable to feed all kinds of standard compression ignited engines requires a chemical plant for carrying out the alcoholysis reaction and processing of the crude glycerin by-product. Economical outputs depend also on market price of this last commodity.

The last technique opening a way for using palm oil as fuel involves catalytic cracking, then allowing to feed any kind of engine -either spark or compression ignited-although a few results are available only from laboratory or small pilot scale experiments. If the economic viability would be favored by scale-up effect for large national or international markets assuming palm oil producing cost would become and remain competitive is spite of lack of harvest mechanization, and oils would remain available for large non food markets, as this is presently the case, there is a lack of technical and economical data. This is especially the case regarding the minimum size required for applying these more sophisticated chemical transformations -alcoholysis and cracking- for supplying energy under most critical conditions found in remote areas where millions of people are facing difficult access to both electric power and transportation fuels.

Today large scale production and marketing of palm oil methyl or ethyl ester is under development in oil palm cropping countries like Malaysia, Thailand or Brazil. The follow-up depends on many parameters on environment, social and economic sides.
\end{abstract}

Key words: palm oil, fuel

useful resources. In this view, lot of scientific reports issued during the last two decades of the $20^{\text {th }}$ Century, deal with the following question: how to use these natural oils for feeding Diesel engines, either (i) in natura and alone (and to which extent should they be refined) or (ii) as mixtures with petroleum based diesel fuel, or (iii) after derivatization into their methyl or ethyl esters, or even(iv) after cracking into petroleum-like hydrocarbons.

These questions address both political and technical issues which are discussed hereafter. Each way shows technical advantages and drawbacks and therefore is more or less attractive under specific conditions according to geographical, economic or political situations.
The technical options are discussed in the next section while other aspects more closely related to current developments in various countries worldwide will be considered in the last section.

\section{Palm oil as an industrial feedstock}

Before entering the topic of biofuels, it is useful to introduce the starting biomass. The world yearly production of vegetable and animal oils exceeds today 120 millions tons. As livestock, about $4 / 5$ of the world production of oils and fats are devoted to food uses, the remaining being for non food uses ie animal feed, soap 
and oleochemicals. Finally the market of vegetable oils (VOs) for energy as a whole is still very low ( 2.5 millions tons/year) but shows a fast increase. However from the current availability -and the most optimistic forecast- need to mention that the portion of VOs that could be allocated to energy production is definitely not in the range of that of today energy sources like wood, mineral oil or coal. In fact the important need for food according to the current demography and which should be regarded as a priority, is promoting alone a fast increase of VOs production worldwide. In addition the reasonable demand for cleaner/safer chemicals such as detergents, lubricants, polymers boosts the market of oleochemicals and thus VOs production. Owing to their natural chemical structure thanks to enzymatic/photosynthesis, industrial oleochemicals require less processing and energy to reach the active forms in comparison to petrochemicals and thus they can compete in spite of their higher price as industrial feedstock. This chemical advantage does not apply similarly in the cases of their fuel uses, but -fortunately- other parameters are also to be considered.

For example two VOs, namely soybean and palm oils, account for about 40 percent of the total oil and fat production, or half the whole production of VOs. It is worthwhile to point out that these two oils belong to very different agronomic and economic systems :

- Soybean is a highly mechanised annual crop, produced mainly in America (USA, Brazil, Argentina) and the cake is a valuable product as an animal feed, to such an extent that depending on market prices, the former often provides more than $50 \%$ of the farmer's income.

- Oil palm is of course perennial, harvested throughout the year; harvest must be done manually and oil palm is grown mainly in South-East Asia (Malaysia, Indonesia); de-oiled fibres are burned but in addition the associated kernel oil is also a valuable product for the manufacture of surfactants and body care products -in fact palm kernel and coconut being the sole source of medium chain fatty acids.

Also the extraction of soybean oil is made through an hexane based process while palm oil (PO) needs only a screw press (no solvent, no associated hazard), the last process being more flexible for adaptation to very small scale (down to $100 \mathrm{~kg} / \mathrm{hr}$ of oil) thus suitable for small holders projects and/or remote areas.

This is an illustration of the specificity of each techno-economic situation one has to face when considering VO based fuels. Out of these two crops one may find a handful of VOs of some importance and many others having local or specific uses only.
From the chemist's standpoint crude VOs are made of about $95 \%$ of triacylglycerols (TAGs, tri-esters of glycerol and fatty acids) but also contains free fatty acids, phopholipids and many other minor components (partial acylglycerols, waxes, sterol esters, pigments, oxidation products). Major VOs which are obtained from a solvent extraction process -but not POare not suitable for direct marketing as food; thus they are processed through many steps to get RBD oil (refined, bleached, deodorized). Although refining of crude palm oil (CPO) would not be required thanks to the solventfree pressure based extraction process, refining is still included in order to extend the shelf life, this because of its high level of free fatty acids, and to meet other demand as well. But the picture might be different for fuel purpose and the extent to which VOs should be refined is still a research topic, as discussed later.

Among the many available parameters, the fatty acid composition of acylglycerols and the lodine Value (IV) provide a good picture of the chemical composition and of the properties of a VO [1]. It can be seen from table 1 that due to the high level of palmitic and oleic acids PO is rather saturated compared to cotton oil (or soybean oil) but still not as saturated as coconut and palm kernel oils - palm kernel oil (PKO) being the second product from this very useful crop. Thus the conclusion is that PO and its derivatives are rather stable towards thermal degradation and oxidation. In addition CPO is naturally preserved against oxidation owing to its high level of natural antioxidants (tocotrienols) which are unfortunately partially removed during refining. Another important fact resulting from the fatty acid composition is that PO is a solid at room temperature and cannot be stored and pumped without appropriate heating of tanks and pipes.

As already written, there are four ways for using VOs as fuels. Neat VO implies to adapt hardware namely the engine while biodiesel (derived methyl or ethyl ester) does not, but biodiesel needs an additional processing, and of course the alcohol -methanol or ethanolmust be available to perform the alcoholysis reaction and obtain the corresponding ester. The main points about the uses of VOs as fuels are highlighted hereafter, based on results available in the bibliography and from the Cirad long standing expertise in the field.

\section{Direct use of PO as Diesel fuel/ technical aspects}

\section{Chemical insight}

It is well known that VOs (actually since Rudolf Diesel) $[4,5]$ and their methyl or ethyl esters can be used in compression ignited engines.

First we need to define which type of PO is to be considered and which parameters should be taken in account. As a matter of fact VO are currently specified for food or as industrial oleochemical feed stocks but surely not as fuels. Very soon the question arise about the need of refining and if so to which extent, this because of the importance of processing cost when talking about so "cheap" feed tocks as tax free petroleum fuel, the unavoidable reference.

For example free fatty acids, phospholipids, phytosterols and diacylglycerols, the normal components of VOs in addition to TAGs should no longer be considered as negligible minor components. Especially, diacylglycerols (DAGs) are the second more important components on the percent weight basis, right after TAGs. As a matter of fact (i) surfactant properties of these compounds are well known emulsifiers currently used in the food industry, (ii) their percentage changes from one oil sample to the next due to different origins, storage/processing conditions and refining processes. This is true in particular for DAGs that can approach or even overpass $10 \% \mathrm{w}$ even after refining because of the variable but generally high acidity of CPO (table 2). It is then justified to investigate separately (i) the TAGs alone as the major components of VOs obtained through a laboratory purification method (flash chromatography, [2]) and (ii) model oils obtained by adding these minor components to TAGs, because above listed minor components may have an influence in

Table 1. Main fatty acids in palm oil and palm kernel oil [2, 3].

\begin{tabular}{|lccccc|}
\hline Fatty Acid & Symbol & Cotton & Palm & P. kernel & Coprah \\
\hline Caprylic & C8 :0 & - & - & $3-4$ & $6-10$ \\
Capric & C10:0 & - & - & 3 & $5-10$ \\
Lauric & C12:0 & - & $<0,2$ & $\mathbf{4 5 - 5 2}$ & $39-54$ \\
Myristic & C14:0 & $<1$ & $1-2$ & $\mathbf{1 4 - 1 9}$ & $15-23$ \\
Palmitic & C16:0 & 24 & $\mathbf{4 3 - 4 6}$ & $6-10$ & $6-11$ \\
Stearic & C18:0 & 2 & $4-6$ & $1-3,5$ & $1-4$ \\
Oleic & C18:1 & 19 & $\mathbf{3 7 - 4 1}$ & $\mathbf{1 1 - 1 9}$ & $4-11$ \\
Linoleic & $\mathrm{C} 18: 2$ & 53 & $9-12$ & $0,5-2$ & $1-2$ \\
Linolenic & $\mathrm{C} 18: 3$ & $<1$ & $<0,4$ & $<0,3$ & $<1$ \\
\hline
\end{tabular}


the range of that of the fatty acid composition itself. Data often found in the literature lack mentioning detailed analytical information and are refereed as "crude", "neutralized" or "refined" oil upon the case, thus providing only limited information.

\section{Low temperature properties}

Regarding the properties of PO as fuel implies considering the various stages the fuel must pass from the tank to the exhaust of an engine or an heater. These steps are summarized in table 3, along with corresponding experimental technique that has been used to characterize the samples.

Compared to petro-diesel fuel (PDF), PO physical and chemical properties in table 4 taken from various bibliographical sources look somewhat different.

The first property to be checked is of course the melting point (and associated low temperature properties like viscosity). Cloud point of 27 $31^{\circ} \mathrm{C}$ is the highest among major oils and far above specification for Diesel fuel even in tropical area (table 4). table 5 displays data relative to two other oils, namely cotton oil which contains also a significant percentage of palmitic acid like PO - although to a lower extent (table 1)- and coconut oil, one of the most saturated oils. The solid fat content of $88 \%$ under cold conditions (table 5) means that PO oil cannot be used out of its tropical production area, just like cotton and copra oils, while soybean oil for example shows a solid fat content of $5 \%$ only and a cloud point of $-9^{\circ} \mathrm{C}$. These special properties of $\mathrm{PO}$ come from the fatty acid composition of acylglycerols, as shown in table 5, because of the high palmitic acid content, and are correlated with the somewhat low lodine Value and very low content of triunsaturated TAGs (ie. TAGs containing only unsaturated fatty acids, known to have a very low solidification temperature) (tables 1,5).

Thus an oil solid at ambient temperature like PO requires several equipments in order to be used as fuel in a Diesel engine :

- a side tank for petroleum Diesel fuel (this to start and stop the engine with PO free pipes),

- an automated dual fuel switch valve,

- an additional pump to feed the standard injection pump,

- several devices to warm up oil tank and pipes, All this to overcome problems driven by high viscosity and high melting temperature.

\section{Ignition - combustion}

If cold temperature properties are important ones, the behavior in the engine itself is also a matter of concern. Since the beginning of the last century engines have been improved to achieve more and more efficiency but of course with the current petroleum derived fuel, and thus not all standard parameters used for hydrocarbon based fuels can be applied for assessing fuel properties of PO or VOs in general.

In fact not all standard fuel specifications listed in table 4 are suitable to assess the true efficiency of a VO as fuel; this is especially the case

of Cetane Number (CN), a parameter linked to the autoignition ability of hydrocarbons but not of acylglycerols $[2,6]$. Quality standard expressed by an index as for petroleum fuel, i.e. $\mathrm{CN}$, is not applicable to VOs and thus for comparing a given oil to PDF. But CN could still be a criterion to compare quality as biofuel within series of VOs $[8,9]$.

Table 2. Detailed chemical composition of refined palm oil and derived purified palm oil TAGs [2].

\begin{tabular}{|lccccccc|}
\hline & $\begin{array}{c}\text { TAG } \\
(\mathrm{w} \%)\end{array}$ & $\begin{array}{c}\text { DAG } \\
(\mathrm{w} \%)\end{array}$ & $\begin{array}{c}\text { MAG } \\
(\mathrm{w} \%)\end{array}$ & $\begin{array}{c}\text { Phospholipids } \\
(\mathrm{ppm})\end{array}$ & $\begin{array}{c}\text { Free fatty acid } \\
(\mathrm{w} \%)\end{array}$ & lodine value & $\begin{array}{c}\text { Peroxide val. } \\
\text { meqO2/kg }\end{array}$ \\
\hline Refined oil & $\sim 91$ & 8.4 & Traces & 175 & 0.06 & 50 & 0.04 \\
$\begin{array}{l}\text { TAG from Flash } \\
\text { Chromato. }\end{array}$ & 99.0 & 1.0 & $\begin{array}{c}\text { Not } \\
\text { detected }\end{array}$ & $<25$ & 0.005 & 50 & 0.02 \\
\hline
\end{tabular}

Table 3. Methodology adopted for investigating properties of vegetable oils as fuels $[3,6]$.

\begin{tabular}{|ll|}
\hline Stage or Phenomenon in engine & \multicolumn{1}{c|}{ Test } \\
\hline Storage & Cloud point, Solid content \\
Injection & Surface tension \\
& Viscosity \\
& Spray, drop size distribution and specific area \\
"Evaporation" of biofuel & Evapostalagmometry (droplet evaporation) \\
& Thermogravimetry \\
Air-fuel mixture & Pre-combustional chemistry \\
Ignition & Ignition delay \\
Combustion & Exhaust gases, Heat release \\
& Power, Carbon deposit \\
\hline
\end{tabular}

Table 4. Properties of petroleum Diesel fuel, RBD Palm oil and Palm oil esters [2, 6-9].

\begin{tabular}{|lcccc|}
\hline & Diesel fuel ${ }^{\text {a }}$ & Palm oil & Palm methyl ester & Palm ethyl ester \\
\hline Hydrocarbons (w\%) & 100 & 0 & 0 & 0 \\
Sulfur content & $1-1.3$ & 0.03 & $<0.04$ & $<0.04$ \\
Total acyl glycerols & 0 & 100 & $<1$ & 2.9 \\
$($ w\%) & & & $321-325$ & 336 \\
Distillation & 230 & - & & \\
$10 \%$ & & & $340-350$ & $340-350$ \\
$\left({ }^{\circ} \mathrm{C}\right)$ & $310-370$ & & & \\
$90 \%$ & & 219 & $171-178$ & - \\
Flash point $\left({ }^{\circ} \mathrm{C}\right)$ & $55-170$ & 38 & 40 & 39.7 \\
Heat value $(\mathrm{MJ} / \mathrm{kg})$ & 42 & 0.91 & 0.87 & 0.88 \\
Density $\left(15{ }^{\circ} \mathrm{C}\right)$ & $0.81-0.87$ & 32 & 4.3 & 4.7 \\
Viscosity $40{ }^{\circ} \mathrm{C}(\mathrm{cS})$ & 2.8 & $27-31$ & 16 & 16 \\
Cloud point $\left({ }^{\circ} \mathrm{C}\right)$ & $0-19$ & $38-40$ & $55-59$ & $51-56$ \\
Cetane number & $45-50$ & & & \\
\hline
\end{tabular}

a Diesel fuel specifications according to country (France - Brazil) and seasonal variations.

Table 5. Cold properties, cloud point and solid content of TAGs vs lodine value and unsaturated TAG content [2].

\begin{tabular}{|lccc|}
\hline TAGs (Flash chromato.) & Cotton & Palm & Coconut \\
\hline Cloud point $\left({ }^{\circ} \mathrm{C}\right)$ & -3 & 27 & 18 \\
Solid fat content at $-20{ }^{\circ} \mathrm{C}(\% \mathrm{w})$ & 35 & 88 & 98 \\
lodine value & 110 & 50 & 12 \\
Unsaturated TAGs ${ }^{\mathrm{a}}(\% \mathrm{w})$ & 37 & 1 & $\sim 0$ \\
\hline
\end{tabular}

a TAGs containing only unsaturated FA). 
The Ignition Delay (ID) measured either in a standard engine or in a constant volume combustion chamber is more closely related to the behaviour of the tested oil. As a matter of fact although PO Cetane Number being substantially lower than the value measured for PDF (respectively $38-40$ and $45-50$; table 6), the ID of PO derived TAG fraction is one of the shortest right after copra oil (respectively 7.9 and 6.8 Crank angle degree), measured in an engine at bench [2]. In the same study standard Diesel fuel is reported to show an ID (in Constant volume chamber) longer than copra and palm oils, as confirmed by Bari et al. [11].

In addition to the above parameters, researchers have investigated a handful of pertinent physical, chemical and physico-chemical properties in order to achieve a better understanding of the origin of these rather interesting properties of $\mathrm{PO}$ :

- Surface tension because of its direct link to spray properties during injection in an engine, - Viscosity in a temperature range close to that of injector i.e. where spray forms,

- Spray data, like average drop diameter; specific spray area, directly linked to rapid contact between biofuel and air in combustion chamber,

- Droplet evaporation; because of the difficult observation in a running engine, for this purpose Cirad researchers designed a special chamber fitted with a digital camera allowing to measure the size of a droplet of oil vs time, at temperature normally observed in an engine (up to $600^{\circ} \mathrm{C}$ ). The technique was named "evapostalagmometry" $[2,6]$. The evaporation coefficient $\mathrm{K}\left(\mathrm{mm}^{2} \cdot \mathrm{s}^{-1}\right)$ used, independent of drop size, is directly linked to the speed at whichy it disappears. The main difference with PDF lies in the increase of the area for oils during the first part of experiment, while within the same period of time a drop of Diesel fuel disappears completely: hydrocarbons do

Table 6. Main injection and combustion fuel properties of palm oil TAGs [3].

\begin{tabular}{|lccc|}
\hline & Cotton & \multicolumn{2}{c|}{ Palm Coconut } \\
\hline $\begin{array}{l}\text { Spray specific area } \\
\left(\mathrm{mm}^{2} . \mathrm{mL}\right)\end{array}$ & 890 & 950 & 1000 \\
K Evaporation at $450^{\circ} \mathrm{C}$ & 0.70 & 1.11 & 2.44 \\
$\left(10^{-3} \mathrm{~mm}^{2} \cdot \mathrm{s}^{-1}\right)$ & $260^{\mathrm{a}}$ & $320^{\mathrm{a}}$ & $420^{\mathrm{a}}$ \\
at $520^{\circ} \mathrm{C}$ & & & \\
$\begin{array}{l}\text { lgnition delay (Crank } \\
\text { angle degree) } \\
\text { Cetane Number }\end{array}$ & 9.0 & 7.9 & 6.8 \\
Carbon Conradson (\%) & $35-40$ & $38-40$ & $40-42$ \\
\end{tabular}

a from [4-6] (under different experimental conditions).

${ }^{b}$ experimental results for palm oil (not purified TAGs) by ASTM D613 method [6]. vaporize while TAGs cannot but instead undergo pyrolysis (table 6).

- Precombustional chemistry, i.e. the compounds issued from pyrolysis during injection and supposed active towards ignition.

- Global performances: torque (Nm), specific fuel consumption $(\mathrm{g} / \mathrm{kWh})$ and global efficiency. All are very close to the data for petroleum diesel fuel if measured in an indirect injection engine or a modified direct injection engine $[2,6]$.

The above parameters are generally in favor of PO, right after copra TAGs, the best among all investigated vegetable oils (table 6) and this is consistent with the conclusion driven from ID. This is also the case for atmospheric pollutants like carbon monoxide, hydrocarbons and nitrogen oxides ( $\mathrm{CO}, \mathrm{HC}$ and $\mathrm{NO}$ x respectively) and Conradson residue, all linked to the efficiency of combustion during engine cycle. All this comes from the lodine Value considered as the simplest and meaningful parameter for the purpose. If Conradson residue is often linked to a high phospholipid content by researchers, this is not likely to be the case for PO owing to the pressure based extraction process which leads to a very low level of these minor components, as this is also the case for palm kernel oils.

The above positive conclusion concerns mainly the "pure" PO TAG fraction; need to mention that it was shown after lab and engine studies [2] that the fuel properties of VOs are even improved when some minor components are included, this probably because of their surface tension lowering effect and subsequent positive effect on spray. This is especially true for diacylglycerols - a class of compounds linked to initial acidity- which leads to a significant improvement. For example RBD PO obtained from a "normal" CPO having a rather high acidity would be a better Diesel biofuel. Thus the content of minor components is an important parameter and the refining stage as well, although authors do not necessarily agree on the various effects.

\section{Miscellaneous trials at bench or field with crude or refined palm oil}

The long standing interest for PO as fuel led mechanical engineers to perform trials with various types of Diesel engines; the most widely reported are of Direct Injection type (DI). It is always possible to run any Diesel engine with neat VO for several tens of hours but the outstanding question deals with long term effects: cocking of injector tip and carbon deposit in combustion chamber. These troubles appear to be strongly linked to engine type: direct-injection engines are much more sensitive to fuel properties than indirectinjection ones. Field trials are currently in progress at Cirad with DI engines after heavy modification of the combustion chamber for improving thermal conditions. We are observing that an increase of the temperature of the walls of the combustion chamber helps to decrease cocking and that above a given temperature there is no more difference between PDF and VOs [12], as also noted by other authors [11, 14-16].

The fact that most of the time oils are defined only as "crude" or "refined" might explain some discrepancy between series of results, in addition to the various operating condition set for running the engines. For example CPO was found to produce reduced levels of pollutants in exhaust gases than ordinary Diesel fuel [16] while RPO gives even less soot content [15] whereas CPO is reported to yield more $\mathrm{CO}$ and NOx [11] than reference fossil fuel. Need to say that VOs in general does not release sulfur containing gases, harmful to human health and environment. In the above study, it was concluded that CPO did not affect the closefitting parts of injection system in spite of the presence of several percents of free fatty acids and other "active" natural chemicals [11]. Authors generally agree that heating the oil to a temperature above $60^{\circ} \mathrm{C} \quad\left(90-100^{\circ} \mathrm{C}\right)$ improves $\mathrm{PO}$ performance, deposit on cylinder heads, etc $[11,13,16,17]$. Evolution of crank case lubricant is also a matter of concern as it affects maintenance cost, but also engine endurance and longevity. Surapol et al. concluded recently that (i) wear metals in the drained engine lubricating oil, (ii) oil thickening and (iii) oxidation "should not be worse than standard Diesel oil" [15] ; it turns out that the drainage of lubricant can be made as for ordinary Diesel fuel, but aditional wear in the piston compression rings was reported after long runs.

In a tentative to balance the high viscosity of PO, other reports show that reverse emulsions (1-3\% water in PO) help decreasing deposit and NOx [14]. When the components are not miscible as a simple binary mixture (case of short chain alcohols and VOs), it is still possible to bring all this together as a micro-emulsion. This reduces the viscosity compared to starting $\mathrm{VO}$, but the main drawback lies in the requirement of at least four components including one surfactant. A work dealing with microemulsion concluded that it is possible to obtain "new micro-emulsions" with PDF and PO through a simple method and at low cost (PDF / PO / water / C2-C5 alcohol / emulsifier and with only a small increase of solid residue as technical drawback; the emulsifier being a soybean derived soap and the short chain alcohol isoamyl alcohol in the above example [17].

These results bring the same problem as they are not generally based on long term trials 
$(1,000$ hours or more). Among several research centers or private companies that did run field trials with an application objective, whatever the results, the Malaysian Palm Oil Board (MPOB, formerly PORIM) owns probably the most extensive expertise with cars. These are fitted with Elsbett type engines, i.e. engines having a special design for using non standard fuels. In Brazil several trials are currently operated with neat VOs in remote areas for communities and including PO plants for electricity production with DI engines.

Cirad applies its scientific and technical results to real world: adaptation of small engines for pumps, cars, tractors, up to electric power plants in factories, as well as heat production, mainly with copra oil in Pacific islands, an oil very similar to palm kernel oil, but also in some cases with PO. These lightly adapted -but still current type- indirect injection engines are granted foul warranty from manufacturer. Malaysia has demonstrated after years of extensive trials and marketing countrywide that RBD palm olein can be used as $5-10 \%$ blends with Diesel fuel [18].

\section{Conclusion}

PO does not have fuel properties as bad as one would expect from a rapid assessment based on its Cetane Number. From our expertise, whatever type of PO being used, once passed cold (filtration) and corrosion tests, we recommend to use only Indirect Injection engines (IDI) which are widely manufactured and spread enough worldwide -although less than DI engines- once only lightly adapted as described in above paragraph,including suitable injectors as advised in reference [13] to adjust temperature and pressure (external devices only; no modification of combustion chamber nor injection system). To our knowledge and practical expertise this overcomes most of the mentioned problems and drawbacks, and can help bringing full warranty from engine manufacturers. Thus it is not required to shift to specially designed engines like Elsbett type nor heavily modified engines as advised elsewhere [16] (neither install a turbo-charger in Diesel engine in order to increase the temperature and pressure inside the cylinders, nor use special lubricants with convenient additives). Also the formulation route through microemulsions looks promising both for lowering the viscosity and for improving other properties by a careful choice of components, but very little work has been done to date with PO or PKO in comparison to liquid oils (for an excellent review see [68]).

\section{Biodiesel, properties of palm methyl or ethyl esters}

The above technical solutions, all aiming to use neat $\mathrm{PO}$, share the common advantage of requiring only limited post-harvest processing. In other situations it is wise to adapt fuel properties to existing hardware (through short chain alcohol esters or catalytic cracking). Climatic, social, political and economic aspects of the topic will be discussed later; the present paragraph deals with technical features of what is now known as "Biodiesel".

\section{Processing}

With the help of a catalyst, the reaction of methyl alcohol (methanol) and a VO yields a methyl ester. Although the change may appear very small from the chemical point of view (starting TAGs are also esters) the difference lies in the average molecular weight of starting and end products, the later being reduced to approximately one third of the original value. For example this allows methyl ester to vaporize as hydrocarbons do upon injection in the engine, whereas TAGs undergo pyrolysis prior to the ignition step, giving the above mentioned advantages and drawbacks. Fuel properties are then significantly affected so that short alcohol esters do not fall in the same fuel group, as shown in table 4, thus justifying the present route.

The methanolysis or transesterification reaction is well known from chemists and even it has been performed at large industrial scale for decades because methyl esters were known and used first as oleochemical commodities for manufacturing other esters and fatty alcohols (for lubricant, detergent and cosmetic uses for example). In fact PO derived esters, namely ethyl esters, where proposed as early as during the 40 s by Chavanne [19] and van den Abeele [20], but this route was almost forgotten before attracting again interest from fuel specialists during the earlier $80 \mathrm{~s}$, for $\mathrm{PO}$ [21] as well as for other oils [22]. Since then Cirad worked quite extensively in the field of PO derived esters, both on the chemical reaction side and on biodiesel properties [23-25] as well as other research groups [26-29].

Starting oil, catalyst, temperature, excess of methanol or ethanol to shift the alcoholysis reaction, were investigated. Need to mention that the last parameter comes from the fact that the reaction is an equilibrium, and because of this an excess of alcohol is necessary although it must then be separated by distillation before recycling. In addition to the above parameters the question arises about the influence of the many components present, even at trace levels, in the crude ester. These may either come from the starting oil (free fatty acids neutralized as soaps in case of a basic catalyst, phytosterols, etc) or be alcoholysis co-products like glycerol itself, partial glycerides coming from a non complete reaction or even untransformed TAGs. All these factors have been extensively investigated for rape, sunflower and soybean Biodiesel in Europe, the USA and Canada and in spite of PO having an acidity higher than seed oils, there is no technical barrier for achieving good yields.

Today the biofuel market is boosting the production of rape methyl esters to such a point that huge plants producing half million tons yearly are already operated in Europe, either of batch or continuous process types, and large plants are also operated in Malaysia with RBD PO. But PORIM for example developed a twostep chemical process to convert also CPO into methyl esters to be used as diesel substitutes $[29,30]$. Because of the presence of high level of free fatty acids in CPO, this process involves two steps, esterification of acids followed by methanolysis of TAGs. It has been successfully evaluated at a $3000 \mathrm{t} / \mathrm{yr}$ capacity pilot plant. Thus there is no doubt about technical feasibility nor even production cost of PO methyl ester (POME), neither for glycerin, the second product of alcoholysis.

Currently methanol is a petrochemical while ethanol is an agricultural product derived from sugar beet and sugar cane after fermentation and distillation in huge agrochemical plants. Ethyl esters of VOs have been known as specialty oleochemicals in the past owing to their use for cosmetic or pharmacy. During the $80^{\prime}$ 's Cirad researchers $[21,23,24]$ worked out a process dealing with manufacture of $\mathrm{PO}$ ethyl ester (POEE), on the basis of its properties as biodiesel as a function of various process alternatives or steps. In the special case of ethanol another question arise about the influence of the water content left after distillation and even further dehydration and there are acceptable technical solution [25]. Still there is an incertitude with plant operating with ethanol, because the separation of glycerin is not as easy as it is with methanol, but technical solutions compatible both with technical and economic constraints will be worked out at industrial level. In addition there are many technical improvements, like the use of a solid acid catalyst for operating on a continuous mode [31], or combined extraction-alcoholysis, that could be introduced if taking in account that this sector is not oriented towards food market but towards industrial uses; thus the overall process could be reset or reformulated, from the seed down to the many valuable chemicals that are or could be produced (in addition of the main esters), but this is another story. Need to mention that minor components resulting from methanolysis reaction of $\mathrm{PO}$ are currently mar- 
keted in Malaysia, thus combining health benefits and economical optimzation of the whole process.

\section{Biodiesel properties}

Regarding fuel properties of PO esters (table 4), the heavier distillation fraction which contains the more critical compounds can vaporize even at lower temperature compared to PDF; viscosity falls close to that of PDF; flash point stays high thus bringing an improved safety during storage; heat content is intermediate between $\mathrm{PO}$ and standard fuel; Cetane Number is significantly higher than for PDF; only cold properties like cloud point falls in the range of PDF specifications in tropical countries and may be critical depending on the climate where PO biodiesel is to be used. Choo et al. [35] also come to same conclusions, about POME and methyl ester from palm stearin; these authors also shows that the corresponding ethyl esters and isopropyl esters bring improved cold properties. Winterization either of starting oil or biofuel can provide an easy way to improve this or even starting from palm olein for exportation to colder countries. Of course mixing with PDF can also solve the problem. For example Kalam et al [26] reported that a mixture of $15 \%$ POME in PDF, with $50 \mathrm{ppm}$ of a corrosion inhibitor, increased brake power and reduced exhaust emissions compared to PDF. It decreases wear metals ( $\mathrm{Fe}, \mathrm{Cu}, \mathrm{Al}$ and $\mathrm{Pb}$ ) and additives (Zn, Ca) depletion; viscosity evolution of lubricant is normal.

First standard compositions for rapeseed esters as Diesel fuel, then specifications were set up $[32,33]$ and thousands of engines are currently fed either with ester alone like city buses in Graz, Austria or with blends [34] to such an extent that there is no doubt about the quality of rape or soy methyl esters marketed today as biodiesel (EU biodiesel standard EN 14 214) and warranty is granted by engine manufacturers.

POME follows the same route, one decade later, and thus benefits from the expertise gained on rape ester in Europe. Thus specifications are now proposed for POME, based on national expertise $[35,36]$. There are road trials currently operating with POME in Malaysia, and in Indonesia with B10 (10\% in PDF) [37, 38] and with POEE in Brazil in private groups or research centers $[39,40]$.

\section{Conclusion}

Knowledge available about POME, either from $\mathrm{RBD}$ or $\mathrm{CPO}$, is now enough to show that these agrichemicals are good PDF substitutes, and they are readily available at industrial scale in Malaysia and Indonesia. Now considering POEE, although lacking -to our knowledgeboth scientific and field results, these can also be considered just like POME as good potentiel PDF substitutes, awaiting for industrial development now planned in Brazil.

\section{Hydrocarbon fuels for all kind of engines from catalytic cracking}

Last but not the least, cracking of TAGs has drawn interest from several research teams over the past decades, although cracking of PO over mineral catalyst was performed during World War II in Western Africa, regions rulled by France and Belgium at that time [41, 42] and even was reported in earlier scientific communication [43].

Thermal cracking or pyrolysis is a very complex set of chemical reactions ending on products like light gases (methane, ethane, butane) but also polymers and charcoal (coke) whereas, in the present case, the prefered products are liquid hydrocarbons [44, 45]. In fact thermal degradation alone is not suitable for that purpose this is why a catalyst is required to achieve complete deoxigenation (ie to obtain only hydrocarbons among the liquid products) and to improve the yield of condensed hydrocarbons (selectivity for liquid fuels) $[46,47]$. Then the chemical composition of products can be adjusted so as to achieve fuel properties as close as needed to those of petroleum derived fuels [48]. Rather sophisticated catalysts can be used in conjunction with hydrogen if Diesel fuel fraction is wanted $[49,69]$, but simpler catalysts like silica, alumina or amorphous aluminosilicates, can also perform cracking in a convenient way $[45,48]$. The catalytic cracking process then yields three interesting fractions, Diesel fuel and gasoline for the condensed products (liquids) and a gaseous fraction having a high heat content also useful as fuel. With cheap aluminosilicates the yield of each fuel fraction is about $25-35 \mathrm{w} \%$ each [45] while yields close to $50 \mathrm{w} \%$ have been reported when using zeolites [50] and more sophisticated mesoporous catalysts [51-57]. Several papers report the possibility of cracking free fatty acid in place of PO itself, then allowing valorisation of glycerol, or distillation condensate, a by-product from PO physical refining process $[44-47,51]$.

The temperature must be kept rather high over $400^{\circ} \mathrm{C}$ and this has of course a negative effect regarding energy consumption of the process but it can be anticipated that gases could find a useful outlet for providing the energy to the process. In such a case it was computed that still $85 \%$ of initial energy content in starting oil would remain available as fuel [58]; this yield, relatively high compared to crude petroleum refining, is due to the fact that the process is reduced to only one step in the former case -no doubt that this is a serious advantage. In addition deactivation coming for continuous coking can be reduced under suitable experimental conditions and the original activity is restored after burning of cokel deposits while resulting combustion heat can be used for running a second reactor for example. Among other advantages, need to mention that the process can be operated continuously at large scale (simultaneous circulation of catalyst and oil), like in modern crude mineral oil refining, or at least semi-continuously, the oil passing through a fixed catalyst bed in this last case. Also most active catalysts are already used extensively in petroleum refining processes, thus they are readily available and at attractive market price; an additional advantage is that quality of starting PO i.e. acidity, has little influence contrary to the two other technical solutions discussed in above sections. Among technical drawbacks: (i) the relatively high temperature of catalytic reactor, although affordable $\left(\sim 450^{\circ} \mathrm{C}\right)$ and definitely lower compared to pyrolysis, (ii) the possible production and release of acrolein a cancer promoter if reactor is not properly operated, and (iii) the production of hydrocarbons itself requires an adapted management, safety devices and procedures (i.e. the process must be operated by a trained chemist).

\section{Conclusion}

Although to our knowledge large scale cracking of a $\mathrm{VO}$ in a petroleum refinery was tried only once during the $80^{\prime}$, there is no doubt that the process could be applied readily to PO on the basis of widespread knowledge for petroleum cracking. Still there is a need for additional results for example about using a crude oil instead of a refined one, i.e. damage to catalyst or adverse fuel properties coming from minor components. However it in this later case it can be anticipated that thanks to the very low content of phosphorus (from phospholipids), because of the pressure based PO extraction process, minor components as a whole should bring less problems in comparison to solvent extracted seed oils; this remark applies also to PKO. Still the cracking of the crude oil coud be performed after a fractionation step for extracting valuable active lipids like vitamins.

Also one of the advantages of the cracking lies in its ability to solve the problem of fuel supply in remote areas where fuel market size might be rather small, but transportation cost very high. It would then be necessary to obtain appropriate data about minimum size required for plant operation as well as equipment and production costs, and pilot results would also be needed for demonstration. 


\section{Economic and social aspects, current status worldwide}

At national level it makes sense to adapt the fuel properties to existing hardware in order to avoid adapting of too many types of engines. This is why ester-fuels have an advantage over direct use of VOs in Diesel engines as it is simpler to perform the chemical reaction at large scale. In addition, worth to mention that methyl esters are then de facto also available for other markets as base oleochemicals, or renewable and biodegradable solvent (phytochemical formulations, cleaning after mineral oil spills, ...). Another aspect deals with the significant encrease of glycerol production, a rather highly priced chemical compared to methanol -the other input for the chemical process. One decade ago there was a question wether the market could absorb this production or the price would collapse, but this did not hapen so far, owing to the possible substitution of polyols by glycerol in many formulations. In addition, new uses are foreseen from current research results as intermediate oleochemical for production of polar environment-friendly solvent, or for polymer synthesis and owing to these emerging markets, price of glycerol will probably decrease at slow rate only.

Rapeseed based fuels started to develop in EU countries during the 90 s, especially in Austria, Germany, France, and, now that the market is well established and riched1.4 million tons in 2003, there is search for new sources -cheaper or leading to new/improved ester properties, like sunflower or used frying oils. Marketing strategy may range from (i) unlabeled fuel like in France on general market, to (ii) special segments where biodiesel holds a dominant position owing to its unique "green" properties, for water-life protection or worker health. The driving forces are on both social/economy and environment sides. If these may vary from one country to the next, they all obey evidently to changes in international policies (trade and environment) and of course to variation of crude petroleum price [59]. To date in fact the last did not play a large role but we are now at the opening of a new era and current petroeum price is reaching the threshold above which biodiesel could compete, with only little or even without no tax incentives, whereas biodiesel was subsidized at about $0.29 \$ / \mathrm{L}$ in the USA in 2003 for exemple.

Another long term trend could also open a market to PO based fuels: the international requirements for shifting to cleaner and renewable energy sources (Kyoto Protocol now coming in force; EU policy planing 20\% of renewable fuels by 2020 [60] for cutting $\mathrm{CO} 2$ production, road transportation being responsible for $84 \%$ ) will increase VOs demand for biofuel as well as use of pollution permit/carbon credit; in both cases PO would benefit, owing to its known "green" and economic advantages (perennial crop/long term storage of carbon, high productivity, low international price). In turn this would help more environmental friendly practices among PO producers, including use of marginal and degraded lands instead of deforestating -case of oil palm in S-E Asia [61] or soybean in Brazil [62]. Also biodiesel helps the national policy of PO producing countries for decreasing PO stocks in times of high supply and lower demand and stabilizing market price. Of course all this complex matrix need to be combined to evolution of other PO markets, food and oleochemicals, for meeting the demand, as well as subsides on both fossil fuel and agricultural products.

Regarding national policies about the last two above points, still conditions are not in favour of POME in Malaysia [18], neither in Brazil, but different countries may chose different ways according to local conditions like dependence on petroleum imports (especially PDF), need for rural development. Thus Malaysia will consider soon implementing a Malaysian Biofuel Act 2005 and is already marketing technology for low pour point POME production plants in containers, for countries like Turkey, Korea, China (Hong Kong). In the mean time, Brazil, the leader expert for nation-wide biofuel policy with its Proalcool programme, has already launched officialy in December 2004 the National Biofuel Programme, for ruling quality specifications, production, and marketing of a $2 \%$ mixture. The project is now at stage of starting the production and the target is all Diesel fuel sold in the country containing $5 \%$ of biodiesel by 2008. Although soybean oil is seen as the sole crop able to answer the demand at present, there are several projects aiming the development of palm plantations on degraded lands in the Amazon region, combining several types of benefits already spoken.

PO biodiesel shares only $1 \%$ of total uses of VOs as fuels worldwide while rapeseed share amounted $84 \%$ in 2003 , but the situation will change soon. In the particular case of Brazil, the country produces five among the major oils, all bringing different physical or chemical properties and advantage could be taken of this diversity to achieve versatile mixtures of ethyl esters, having an optimized composition according to several parameters, like seasonal production, cold properties, lubricating effect and transportation cost as well, POEE being one of these components. The situation may be analog to some extent in other producing countries in Asia like Indonesia, but reasonably not in a majority of countries, either in Asia or Africa, being net VO importer, in spite of their low oils and fats per capita consumption (about 7-11 kg per capita per year compared to $50 \mathrm{~kg}$ in the USA and EU, expressed as total food and non-food uses [63]).

Need to mention that (i) Brazil relies partly on imported PDF for its road transportation through a territory being in fact a subcontinent, (ii) the importation is increasing very rapidly for accompanying its current development and (iii) transportation of PDF itself to remote areas can amount three times the initial fuel price in urban centers [64]. These conditions play in favour of the use of VOs as fuels, independently of international PDF trade price. Here the interest of biodiesel and of biofuel based on VOs clearly escapes the general market by taking in account very special local conditions and it makes sense to see Amazonia as one of the most dedicated region for implementing pilot projects [65] because of its "continental island" character by analogy with Pacific islands where we conduct a handful of pilot projects mainly with electric set generators operated with copra oil. In Amazonia oil palm Elaieis guineensis feels a bit home (native "Caiaué" palm belongs to the same genus) among a wide range of native palms growing as if they were real plantations in large places, all these palms being a potential source of oil for energy use $[39,66]$.

Under remote conditions which is the case now considered, all technical solutions refereed in this paper do not display the same advantage regarding the ease for application, for example POEE requires the availability of the alcohol and of the catalyst (soda) in addition to PO, as well as an expert chemist. Not mentioning the problem of storing large volumes of ethanol regarding public health and security aspects. Thus the ester process can be implemented only in urban centers of some importance as this is likely to be the case for the less known cracking process. While ester brings a convenient solution whenever large volumes of fuel are consumed in a relatively small area and when both oil and alcohol are available, the use of vegetable oils in natura is suitable, for example, in small communities spread in remote areas or in case of in-farm consumption. Then the fuel can be transported over a reasonable distance, shorter than for supplying PDF, until the far end user in isolated communities. Once operating the cracking does not requires other feedstock or chemical than the starting oil, whatever its acidity, and it allows to feed all types of standard engines. Neat PO at the opposite does require only a limited technical expertise for operating the press and other steps of extraction process and is convenient for feeding relatively large power plants in large but remote cities, as Amazonia counts hundreds of them. 
Need also to be mentionned that one ton of oil palm fresh fruit bunches yield $240 \mathrm{~kg}$ of empty fruit bunches, $140 \mathrm{~kg}$ of fibres, $60 \mathrm{~kg}$ of shells. Thus beside crude oils, this crop provides a significant amount of solid biomass, only partly used today in boilers for plant energy requirement, but the utilization with improved combustion process and on a larger scale could also contribute to provide a clean, renewable energy source that could improve the environment, economy and energy security; at present, cogeneration plants using palm oil waste (fibre and shell) is being considered by the Malaysian government [67]. Another aspect which is only starting to be considered and could improve the overal economics deals with the use of this biomass as chemical feedstock for production of carbohydrates, alcohols and other useful chemicals (additives, polymers...). Palm oil mill effluent also can be considered as a source of environment problems or as a source of biomass to be valorized, including for methane production, depending on the way the question is handled.

Of course, any substitution of petroleum for fuel, even more than for a chemical use, needs a strong political commitment and incentives, in addition to locally favorable conditions either on the financial, social, environment or geographical sides.

\section{Prospects}

From a technical point of view, there is a wide panel of solutions for energy generation from $\mathrm{PO}$, and these can fit various local conditions. Owing to the R\&D work carried out under partnership by manufacturers and research centres, VOs fuels including PO are no more an idea still in the mind of researcher nor a fancy spare solution workable only in a few places in the world. The driving forces listed above (self sufficiency, environment concern, rural development...) will help to take advantage of local conditions (macro and micro levels, agroindustrial plant, small-holders association, large estate, remote village, regional politics) to develop energy generation from VOs.

Although the demand of VOs for food is expected to grow rapidly during the next decades because of demography, intensive farming will still supply more oils. Today, governments of industrialized countries are obliged to rule, in order to avoid overproduction and market collapse. Also the demand for cakes (soybean, sunflower, coconut) as cattle feed market is growing faster than the VOs demand, might shift VOs from main product to a side-product status, and could face market problems, thus increasing availability on non food markets.

Environment preservation is a matter of concern and a major political issue (30\% increase of $\mathrm{CO}_{2}$ in air during the last 2 centuries, $145 \%$ increase of $\mathrm{CH}_{4}$ ). As a result governments are putting more and more pressure and taxes on all kinds of pollution makers (Clean Air Act in US, TGAP-Ecotax in France). All this helps the shift to cleaner energy sources, among which PO has to play a role not only because of its attractive physical and chemical properties but also owing to its highest yield among oleaginous to date, for shifting as much and faster as possible to closed carbon cycle transportation fuels. Life cycle assessment which helps to quantify the true environment benefits and its improvement, as well as tax incentives and green policies (like "pollution permits" at international level) will play a key role in the developement of palm oil as fuel.

\section{REFERENCES}

1. DUNN RO, KNOTHE G, BAGBY MO. Recent Advances in the Development of Alternative Diesel Fuel from Vegetable Oils and Animal Fats. Recent Res Devel Oil Chem 1997; 1: 31-56.

2. CHIRAT N. Etude de la qualité de carburants dérivés des huiles végétales - Approche méthodologique, (Investigation on Quality of Fuels Derived of Vegetable Oils - A methodological Approach). (PhD Thesis) University of Montpellier, France (1996).

3. JACQUEMARD J]. Le palmier à huile (The Oil Palm). Paris: Maisonneuve et Larose Editor, 1995.

4. DIESEL R. The Diesel Oil-Engine, Engineering, (1912) 93:395-406 (1912). Chem Abstr 1984; 6.

5. KNOTHE G. In: Knothe G, Kralh J, Van Gerpen J, eds. The Biodiesel Handbook. Peoria: AOCS Press, 2005: 2-10.

6. VAITILINGOM G. 1992. Huiles végétales - biocombustible Diesel - Influence de la nature des huiles et en particulier de leur composition en acides gras sur la qualité-carburant. (PhD Thesis), University of Orléans, France.

7. GRAILLE J, LOZANO P, PIOCH D, GENESTE P Essais pilotes d'alcoolyse d'huiles végétales avec des catalyseurs naturels pour la production de carburants diesel. Oléagineux 1986; 41: 457-64.

8. RYAN III TW, STAPPER B. Diesel Fuel Ignition Quality as Determined in a Constant Volume Combustion Bomb. SAE Technical Paper 1987; (Series 870586).

9. RYAN III TW, CALLAHAN T]. Engine and Constant Volume Bomb Studies of Diesel Ignition and Combustion. SAE Technical Paper 1988; (Series 881626)

10. GUIBET JC, MARTIN B. Carburants et moteurs. Paris: Ed. Technip, 1987.
11. BARI S, LIM TH, YU CW. Effects of preheating of crude palm oil (CPO) on injection system, performance and emission of a diesel engine. Renewable Energy 2002; 27: 339-51.

12. VAITILINGOM G, HIGELIN P, ANDRZEJEWSKI ], SAPINSKI A. Influence du nitrate d'hexyle et de la température de l'air admis sur les délais d'inflammation des huiles végétales dans un moteur diesel (Influence of Hexyl Nitrate and Air Temperature on Ignition Delays of Vegetable Oils in a Diesel Engine). Entropie 1992: 161.

13. RYAN III TW, ERWIN J. Effects of Fuels Properties and Composition on the Temperature Dependent Autoignition of Diesel Fuel Fractions. ASAE Technical Paper 1992; (Series 922229).

14. KALAM MA, MASJUKI HH. Emissions and deposit characteristics of a small dieseln engine when operated on preheated crude palm oil. Biomass and Bioenergy 2004; 27: 289-97.

15. RAADNUI S, MEENAK A. Effects of refined palm oil (RPO) fuel on wear of diesel engine components. Wear 2003; 254: 1281-8.

16. DE ALMEIDA SCA, BELCHIORA CR, NASClMENTO MVG, DOS L, VIEIRAB SR, FLEURY G. Performance of a diesel generator fuelled with palm oil. Fuel 2002; 81: 2097-102.

17. NEUMA DE CASTRO DANTAS T, DA SILVA AC, NETO AAD. New microemulsion systems using diesel and vegetable oils. Fuel 2001; 80: 75-81.

18. BASIRON Y. Biofuel: an Alternative fuel in the Malaysian Scenario. Malaysian Oil Science and Technology 2004; 13: 9-10.

19. CHAVANNE G. Sur un mode d'utilisation possible de l'huile de palme pour la fabrication d'un carburant lourd (A Method for Possible Utilization of Palm Oil for the Manufacture of Heavy Fuel). Bull Soc Chim 1943; 10: 52-8.

20. VAN DEN ABEELE M. L'huile de palme matière première pour la préparation d'un carburant lourd utilisable dans les moteurs à combustion interne (Palm Oil as Feedstock for the Manufacture of a Heavy Fuel for Diesel Engines). Bull Agric Congo Belge 1942; 33: 3-90; (Chem. Abstr. 1944;38:28051).

21. GRAILLE J, LOZANO P, PIOCH D, GENESTE P, GUIDA A. Esters méthyliques ou éthyliques comme carburants Diesel de substitution (Methyl or Ethyl Esters as Alternative Diesel Fuels). Oléagineux 1982; 37: 421-4.

22. SCHWAB AW, BAGBY MO, FREEDMAN B. Preparation and Properties of Diesel Fuels from Vegetable Oils. Fuel 1987; 66: 1372-8.

23. GRAILLE J, LOZANO P, PIOCH D, GENESTE P. Essais pilotes d'alcoolyse d'huiles végétales avec des catalyseurs naturels pour la production de carburants diesel. Oléagineux 1986; 41: 457-64.

24. GRAILLE J, LOZANO P, PIOCH D. Essais d'alcoolyse d'huiles végétales avec des catalyseurs naturels pour la production de carburants diesel. Oléagineux 1985; 40: 271-6. 
25. GRAILLE J, LOZANO P, PIOCH D, GENESTE P, FINIELS A, MOREAU C. Ethanolyse de l'huile de colza en milieu basique non anhydre. Rev Fse Corps Gras 1985; 32: 311-6.

26. KALAMA, MASJUKI HH. Biodiesel from palmoil-an analysis of its properties and potential. Biomass and Bioenergy 2002; 23: 471-9.

27. CHOO YM, CHEAH KY, MA AN, HALIM A. In: Appelwhite TH, ed. Conversion of Crude Palm Kernel oil into Its Methyl Ester on a Pilot Plant Scale, Proceedings of World Conference on Oleochemicals in the 21st Century. Champain, USA: AOCS Press, 1991: 292-5.

28. MASJUKI H, ZAKI AM, SAPUAN SM. Methyl Ester of Palm Oil as an Alternative Diesel Fuel, in Fuels for Automotive and Industrial Diesel Engines, Proceedings of the 2nd Mechanical Engineers Seminar Institute of Mechanical Engineers, London. 1993; (pp 129-137)

29. CHOO YM, MA AN, BASIRON Y. Preparation and evaluation of palm oil methyl esters a diesel substitute. Elaeis 1995: 5-25; (Special issue).

30. ONG ASH. Choo YM, Cheah KY, Bakar A. Production of alkyl esters from oils and fats. Australian Patent (1992), No. AU 626014.

31. LECLERCQ E, FINIELS A, MOREAU C. Transesterification of Rapeseed Oil in the Presence of Basic Zeolites and Related Catalysts. I Am Oil Chem Soc 2001; 78: 1161-5.

32. WWW.BIODIESEL.AT, WWW.BIODIESL.DE, WWW.UFOP.DE, WWW.BIODIESEL.ORG, WWW.BIODIESELBRASIL.COM.BR.

33. PRANKL H, WÖRGETTER M. Standardisation of Biodiesel on a European Level, Proceedings 3rd European Motor Biofuels Forum. 1999; (Brussels, Belgium).

34. MEYER S, KOERBITZ W. Worlwide review of biodiesel production and studies on biodiesel production plants in Europe. Malaysian Oil Science and Technology 2004; 13: 11-6.

35. CHOO YM, YUNG CHEEL, CHENG SIT FOONA, MA AH NGANA, CHUAH CHENG HOOK, YUSOF BASIRON. Key fuel properties of palm oil alkyl esters. Fuel 2005; (accepted).

36. CHOO YM, MAAN, ONG ASH. Biofuel. In: Gunstone FD, Padley FB, eds. Lipids:industrial applications and technology. New York: Marcell Dekker Inc., 1997: 771-85.

37. "BPPT TESTS BIODIESEL FUEL ON DIESELPOWERED BUSES". The Jakarta Post, 2004; (28 septembre).

38. WEB SITE: WWW.MPOB.GOV./BIOFUEL_POIL.

39. DA COSTA RC. Potential for producing bio-fuel in the Amazon deforested areas. Biomass and Bioenergy 2004; 26: 405-15.

40. WEB SITE. www.agropalma.com.br.
41. CHAVANNE G. Sur un mode d'utilisation possible de l'huile de palme à la fabrication d'un carburant lourd (A way for using palm oil for manufacturing a heavy fuel). Bull Soc Chim 1943; $10: 52-8$

42. BONNEFOI J. Nature of the Solid, Liquid, and Gaseous fuels, which Can Be Obtained from the Oil Palm Fruit. Chem Abstr 1945; 39: 31411.

43. MORELL JC, EGLOFF G, FARAGHER WF. Cracking of Palm Oil. / Chem Soc Chem Ind 1932; 51: 133-14T; (Chem. Abstr 1932;26:3650).

44. BILLAUD F, ANH KIET TRHAN MINH, LOZANO P, PIOCH D. Etude paramétrique du craquage de l'oléate de méthyle, (Parametric Study of the Cracking of Methyl Oleate). $C R$ Chimie 2004; 7: 91-6.

45. RASOANATOANDRO C. Transformation des huiles végétales par voies thermique et catalytique (Thermal and Catalytic Processing of Vegetable Oils), (PhD thesis), University of Montpellier 2, (1986).

46. BILLAUD F, GUYTARDY, TRAN MINH AK, ZAHRAA O, LOZANO P, PIOCH D. Kinetics sutudies of catalytic cracking of octanoic acid. / Mol Catal Chem 2003; 192: 281-8.

47. BILLAUD F, TRAN MINH AK, LOZANO $P$, PIOCH D. Catalytic Cracking of Octanoic Acid. Journal of Analytical and Applied Pyrolysis 2000; 58-59: 605-16.

48. PIOCH D, LOZANO P, RASOANANTOANDRO MC, GRAILLE J, GENESTE P, GUIDA A. Biofuels from catalytic cracking of tropical vegetable oils. Oléagineux 1993; 48: 289-92.

49. DA ROCHA FILHO GN, BRODSKID, DJÉGAMARIADASSOU G. Formation of Alcanes, AlkyIcycloalcanes and Alkylbenzenes During Hydrocracking of Vegetable Oils. Fuel 1993; 72: 543-9.

50. WEISZ PB, HAAG WO, RODEWALD PG. Catalytic Production of High Grade Fuel (Gasoline) from Biomass Compounds by Shape-Selective Catalysis. Science 1979; 206: 57-8.

51. YEAN-SANG OOI, RIDZUAN ZAKARIA, MOHAMED AR, SUBHASH BHATIA. Catalytic conversion of palm oil-based fatty acid mixture to liquid fuel. Biomass and Bioenergy 2004; 27: 477-84.

52. YEAN-SANG OOI, RIDZUAN ZAKARIA, MOHAMED AR, SUBHASH BHATIA. Synthesis of composite material MCM-41/Beta and its catalytic performance in waste used palm oil cracking. Appl Catal Gen 2004; 274: 15-23.

53. FAROUQAA, TWAIQ, MOHAMED AR, SUBHASH BHATIA. Performance of composite catalysts in palm oil cracking for the production of liquid fuels and chemicals. Fuel Process Technol 2004; 85: 1283-300.
54. LIMA DG, SOARES VCD, RIBEIRO EB, et al. Diesel-like fuel obtained by pyrolysis of vegetable oils. Journal of Analytical and Applied Pyrolysis 2004; 71: 987-96.

55. TWAIQA FA, NOOR ASMAWATIM, ZABIDIB, MOHAMED AR, SUBHASH BHATIAA. Catalytic conversion of palm oil over mesoporous aluminosilicate MCM-41 for the production of liquid hydrocarbon fuels. Fuel Process Technol 2003; 84: 105-20.

56. TWAIQA FA, MOHAMED AR, SUBHASH BHATIA. Liquid hydrocarbon fuels from palm oil by catalytic cracking over aluminosilicate mesoporous catalysts with various $\mathrm{Si} / \mathrm{Al}$ ratios. Microporous and Mesoporous Materials 2003; 64: 95-107.

57. LENG TY. Catalytic conversion of palm oil to fuels and chemicals. Can / Chem Eng 1999; 77: 156-62.

58. PIOCH D. Unpublished Results, Cirad-IRHO Internal Report, 70. 1993.

59. LICHT FO. World of Biodiesel 2005, in F.O. Licht's World Ethanol and Biofduels Report, 3-13, 1-10 (2005); www.agra-net.com.

60. WWW.EBB EU.ORG/LEGIS/OJ\%2OPROMOTION\%FR.PDF.

61. ANONYMOUS. Dayaks charged in oil palm dispute, Down to Earth No. 42, August. 1999.

62. THE BITTER FRUIT OF OIL PALM. World Rainfortest Movement, Montevideo - Uruguay; www.wrm.org.uy/plantations/material/ oilpalm.html\#about.

63. GUNSTONE F. Agricultural Supplies of Oils and Fats Do not Meet Nutritional Demands. Malaysian Oil Science and Technology 2004; 13: 1-8.

64. AGUIAR F, BULHOES AC, PERIERA AL. Biodiesel: Aspectos Gerais (Biodiesel: General Aspects), www.mbdobrasil.com.br.

65. PINTO RJ. Dendê vai gerar energia em comunidade no Pará. Gazeta Mercantil Biocombustível 2004; (08/12/).

66. SEIBERT M, WILLIAMS G, FOLGER G, MILNE T. Fuel and chemical co-production from tree crops. Biomass 1986; 9: 49-66.

67. HARIMIAM, MEGAT AHMADB MMH, SAPUANB SM, AZNII. Numerical analysis of emission component from incineration of palm oil wastes. Biomass and Bioenergy 2005; 28: 339-45.

68. DUNN RO. In: Knothe G, Kralh J, Van Gerpen J, eds. The Biodiesel Handbook. Peoria: AOCS Press, 2005: 245-58.

69. GUSMÃO JD, BRODSKI D, DJEGAMARIADASSOU G, FRETY R. Utilization of Vegetable Oils as an Alternative Source for DieselType Fuel: Hydrocracking on Reduced $\mathrm{Ni} / \mathrm{SiO}_{2}$ and Sulfided Ni-Mo/ $/ \mathrm{Al}_{2} \mathrm{O}_{3}$. Catal Today 1989; 5: 533-44. 